\title{
Intra- and Inter-population Variability and Evaluation of the Physical Development of a Young Generation
}

\author{
Yulia A. Yampolskaya \\ Research Institute of Hygiene and Health Care of Children and Adolescents, Scientific Center of \\ Children's Health, Russian Academy of Medicine, Moscow, Russia
}

\begin{abstract}
This study is concerned with long-term anthropometric examinations of children and adolescents aged 3-17 years in Moscow (over 10,500 persons, longitudinal and cross-sectional). Population variability of physical development was analyzed by means of regional estimation tables, which were developed on the basis of a regression analysis (scale of the regression of body mass to body length within a range from $\mathrm{M}-1 \sigma_{\mathrm{R}}$ to $\mathrm{M}+2 \sigma_{\mathrm{R}}$ ) and used for individual and group diagnostics taking into account age and sex. Such an approach allowed for the determination of the dynamics of the variability of Moscow schoolchildren from decade to decade (inter-population variability) and variations due to social differences (intra-population variability). $J$ Physiol Anthropol Appl Human Sci 24(4): 503-506, 2005 http://www.jstage.jst.go.jp/browse/jpa
\end{abstract}

[DOI: 10.2114/jpa.24.503]

Keywords: population variability, physical development, standardization, regression analysis, regional differences, estimation tables

\section{Introduction}

In the growing number of studies on human ecology the works concerning children's development have more importance as they are the most sensitive part of the population to environmental changes.

Materials collected during the examination of children and adolescents from different groups of the population in different years are aimed at characterizing the variability in the parameters of the young generation, at determining the influence of environmental factors on its development, and at finding out specific patterns of intra- and inter-population variability.

Numerous scientific publications describe the range of the variability in physical development of the rising generation in Russia for the last decades of the 20th century influenced by environmental factors (Godina et al., 1990; Godina, 2001;
Sukhanova, 1996; Maximova, 1999; Mikhaylova, 1996; Yampolskaya, 1998, 2000, etc.).

In most cases comparative analysis of means and percentiles of the anthropometric parameters has been conducted. At the same time a proper comparison does not seem possible without the unification of evaluation techniques, without the creation of so-called estimation tables allowing us to discriminate between the "standard" and deviations in physical development. Estimation tables must be representative (in numbers and regional patterns), relevant (to be used for the description of that population on which they were constructed) and to get renewed every 15-20 years. In addition, they must meet the three conditions formulated by the WHO as obligatory for mass studies: to be characterized by availability of use, reliability and orientation to the solution of concrete tasks (Wilson, 1975).

The main indices of physical development in children and adolescents are height and body mass, which characterize the rates of growth in length and metabolic level of the growing organism. Proper and timely information is required for the evaluation of an individual and population growth.

\section{Methods}

At the Research Institute of Hygiene and Health Care of Children and Adolescents the analysis of different methods and approaches to the evaluation of the physical development of the young generation has been carried out since the 1960s. They must meet the tasks of individual and group diagnostics. In particular, data on children and adolescents aged 3-17 (over 10,500 individuals, examined longitudinally and crosssectionally) were computed by regression analysis as the most appropriate technique.

Estimation tables are developed by means of the regression equation

$$
y=a+b \times x
$$

where $\mathrm{y}$ is body mass (a dependent variable) and $\mathrm{x}$ is height or 
body length (an independent variable).

The equation allows us to estimate the body mass changes with an increase of body length by $1 \mathrm{~cm}$. The following standardized statistical parameters are necessary for developing the tables: means of body mass (My), means of body length $(\mathrm{Mx})$, standard deviations of body mass $\left(\sigma_{\mathrm{y}}\right)$ and body length $\left(\sigma_{\mathrm{x}}\right)$, and the correlation coefficient between body mass and length (r). It is also necessary to calculate the coefficient of the regression of body mass by body length $\left(\mathrm{Ry} / \mathrm{x}=\mathrm{r} \times\left\{\sigma_{\mathrm{y}}: \sigma_{\mathrm{x}}\right\}\right)$ and the partial standard deviation of body mass $\left(\sigma_{\mathrm{R}}=\sigma_{\mathrm{y}} \times \sqrt{1-\mathrm{r}^{2}}\right)$. In the dual correlation equation, $\mathrm{a}=\mathrm{My}-\mathrm{Mx} \times \mathrm{b}$, where $\mathrm{b}=\mathrm{Ry} / \mathrm{x}$. In the estimation table the criterion of the variability of body length is $\sigma_{\mathrm{x}}$, the criterion of the variability of body mass $\sigma_{\mathrm{R}}$.

This method of developing the estimation tables has been traditional in Russia since the 1930s, but its use often met definite objections. The principal objection is that the marked right-side asymmetry of the distribution is typical of the dependent parameter of the regression equation that is body mass, and so the evaluation based on the principle of symmetry ("standard" $=\mathrm{M} \pm 1 \sigma_{\mathrm{R}}$ ) can lead to a mistake. Furthermore, the constancy of $\sigma_{\mathrm{R}}$ with high and low stature and ignoring the connection between body mass and chest circumference are errors of a regressive method.

However, our analysis has shown that the mistake stipulated by the constant $\sigma_{\mathrm{R}}$ in the groups of tall and short children does not exceed $0.4 \%$. The presence of asymmetry in the distribution of body mass only in $10-15 \%$ of cases can lead to misrepresentation of the results. This mistake associated with the fact of the right side asymmetry in the distribution of the values of body mass is successfully subdued by the extension of the upper border of the "standard" in the estimation tables by $\mathrm{M}+2 \sigma_{\mathrm{R}}$. The range of body mass from $\mathrm{M}-1 \sigma_{\mathrm{R}}$ to $\mathrm{M}+2 \sigma_{\mathrm{R}}$ for the given values of height can be considered as a scientifically based "standard" of physical development, because it covers different somatotypes including children with a developed muscular system and heavy skeletal system, as well as endomorphs without redundant fat deposits.

This scheme has been approved many times on different groups of children and has been offered for practical health care as a screening test in primary diagnostics. With its help we can find children with physical development corresponding to the "standard" (body mass with limits from $\mathrm{M}-1 \sigma_{\mathrm{R}}$ to $\mathrm{M}+2 \sigma_{\mathrm{R}}$ relative to a given height, age and sex), with deviations deriving from insufficient body mass $\left(<\mathrm{M}-1 \sigma_{\mathrm{R}}-\right.$ "deficiency") or excess body mass ( $>\mathrm{M}+2 \sigma_{\mathrm{R}}$ - "surplus"), as well as with short stature (body length below $\mathrm{M}-2 \sigma_{\mathrm{x}}$ ).

Studies carried out in different regions of Russia have proved the reliability and informativness of this approach to physical development evaluation.

\section{Results}

The materials presented here are the results of many years of dynamic observations (from the 1960s to 2004) of the physical development of Moscow schoolchildren.

These observations allow us to pinpoint the beginning of a positive secular trend (acceleration) in the growth and development of Moscow's young generation in the 1960s, its peak in the middle of the 1970s, elements of a negative trend in the 1980s and its development in the 1990s.

The materials testify that the rates of acceleration in height, which were sufficiently high in Moscow schoolchildren in the middle of the 20th century, have considerably reduced since the 1980s. From the early 1990s Moscow school children began to lag behind the schoolchildren of the same age of the previous decades.

We can see the picture of changes in physical development of 16-year-old Moscow boys and girls in Fig. 1.

In the last decade school education in Russia lost its uniformity. New kinds of educational institutions have appeared: lyceums, gymnasia, private schools and others. Examination of the students from some of these schools carried out in the middle of 1990s and in 1998-2002 showed an increase in the number of individuals with a body mass deficiency.

Results of the evaluation of children's physical development in Moscow schools is shown in Table 1.

The types of schools are as follows: I-a school with a special English language course (examined in the 1970s); IIa general education school (examined in the 1970s); III-two schools with extended day studies (examined in the 1970s); IV - a boarding school for children with hearing defects (examined in the 1980s); V-three new-type schools: lyceum and pedagogical gymnasia (examined in the 1990s); VI- two general education schools (examined in the 1990s); VII-four new-type schools-gymnasia and a mathematics school (examined in the period 1998-2002).

As can be seen from the table, the physical development of the students in different educational institutions varies in different years. In Groups I and II ("English" and schools of general education of the 1970s) the leading trend is excessive body mass, whereas the body mass deficiency happened more often in Groups III and IV ( an extended day school and a boarding school for hearing-impaired children). As to the schoolchildren of the 1990s, their status is significantly worse than it was earlier - the body mass deficit became a general trend both in general education schools (VI) and in schools of the new type (V,VII).

\section{Discussion}

Population variability of physical development in Moscow schoolchildren was studied in this paper. The changes in the sexual maturation process or in functional parameters of the young generation for the last 40 years are not considered here. The focus of attention is on the analysis of an integral, estimated characteristic of physical (somatic) development.

Assessment of the physical development of Moscow students according to the estimation tables showed the fact that 


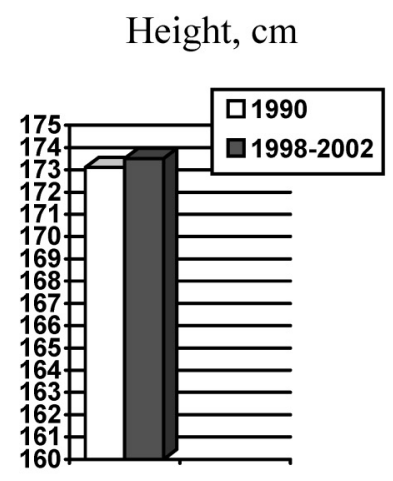

Body weight, $\mathrm{kg}$

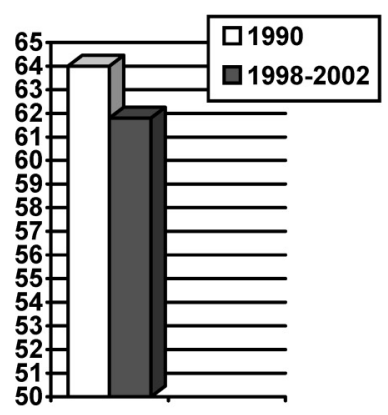

Girls

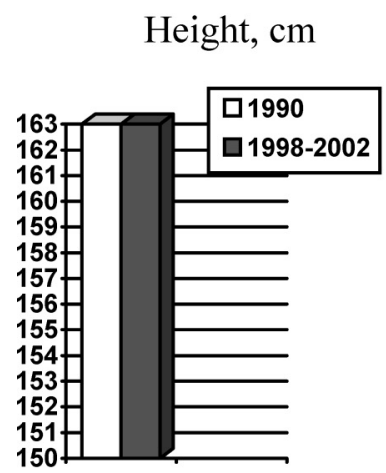

Boys

Chest circumference, $\mathrm{cm}$

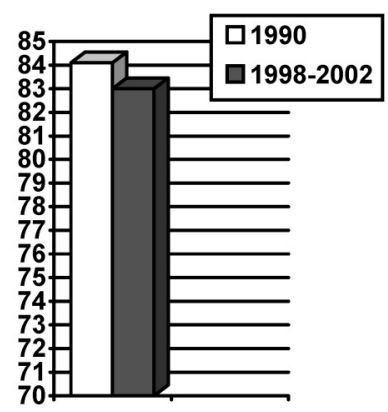

Fig. 1 Changes in body dimensions of 16-year-old Moscow schoolchildren for the last decade.

Table 1 Evaluation of physical development of students in Moscow schools in different decades (Proportion, \%, of children in the following categories)

\begin{tabular}{cccccc}
\hline $\begin{array}{c}\text { School } \\
\text { type }\end{array}$ & $\begin{array}{c}\text { Number } \\
\text { of } \\
\text { children }\end{array}$ & "Standard" & $\begin{array}{c}\text { Excess of } \\
\text { body } \\
\text { mass }\end{array}$ & $\begin{array}{c}\text { Deficit of } \\
\text { body } \\
\text { mass }\end{array}$ & $\begin{array}{c}\text { Short } \\
\text { stature }\end{array}$ \\
\hline I & 611 & 81.8 & 11.6 & 4.9 & 1.7 \\
II & 709 & 79.0 & 10.5 & 8.6 & 1.9 \\
III & 1150 & 79.5 & 5.2 & 13.3 & 2.0 \\
IV & 257 & 77.3 & 6.6 & 11.0 & 5.1 \\
V & 1080 & 73.8 & 8.2 & 16.7 & 1.3 \\
VI & 1003 & 75.0 & 7.0 & 15.0 & 3.0 \\
VII & 1037 & 71.0 & 5.4 & 23.6 & - \\
\hline
\end{tabular}

the category of normal physical development had been reduced from $82.8 \%$ to $79.8 \%$ in boys and from $86.3 \%$ to 82.8 in girls during the period from the mid-1970s to the mid-1990s. At approximately the same time the number of children with excessive body mass has been reduced from $10.2 \%$ to $6.6 \%$ among boys and from $9.1 \%$ to $4.5 \%$ among girls. Simultaneously, the number of schoolchildren with a body mass deficit nearly doubled in boys from $7 \%$ to $13.6 \%$ and in girls increased from $4.6 \%$ to $12.7 \%$.

Cross-sectional observations of schoolchildren of different age and sex groups in recent years (1998-2002) supported the trend towards the increase of the proportion of subjects with a body mass deficiency in the Moscow population. This trend is more evident in teenage groups (14-17). The results of the latest examinations (2002-2004) show that in 15-17-year-old students from Moscow municipal schools the deficit of weight equals, for both sexes, $20.5 \%$.

It should be mentioned that the number of children with short stature also increased and most of the children had a delay in physical development. Though their proportion is small and does not reach $1.5 \%$, it should not be neglected by society because this group represents children from an unfavorable family background and from orphanages (Milushkina, 2002).

From Table 1 we can see the changes in physical status of children from different educational institutions and in different years of observations. In the 1970s the major trend for the schools of the 1st and 2nd types was an excessive body mass, while in the 3rd and 4th types (socially more deprived children), a body mass deficit was more characteristic. In the 1990s the leading trend, irrespective of the school type, is a body mass deficit.

Thus, we can conclude that the evaluation of physical development according to the regional regression estimation tables can be considered a reliable instrument of the 
monitoring of children's somatic status and for revealing various trends in their development.

\section{References}

Godina E (2001) Dynamics of height and development processes in humans: spatial-temporal aspects. (Doctoral Thesis of Biological Science), Moscow [In Russian]

Godina E, Zadorozhnaya L (1990) Influence of some environmental factors on somatic development of children and adolescents. Voprosi Anthropologii 84: 18-30 [In Russian]

Maximova T (1999) Physical development of Russian children (conformities, trends, problems). Materials of the $\mathrm{V}$ Congress of Pediatricians of Russia "A healthy child". Moscow, 16-18 February: 277-278 [In Russian]

Mikhaylova S (1996) Peculiarities of the health state of schoolchildren in Gorny Altay. Moscow, 354 [In Russian]

Milushkina O (2002) Sanitary-epidemiological well-being of institutions for children-orphans and its relationship with the physical development and health status of pupils. (Ph.D. Thesis) [In Russian]

Sukhanova N (1996) Physical development of children and adolescents at the end of the 20th century: the relationship with biological and socio-economical factors. (Doctoral Thesis of Medical Science), Moscow [In Russian]

Yampolskaya YuA (1998) Physical development of schoolchildren in Moscow (longitudinal study of 19821991). Materials on physical development of children and adolescents of urban and rural areas of Russian Federation 5, Moscow, 34-44 [In Russian]

Yampolskaya YuA (2000) Physical development of schoolchildren-inhabitants of a megalopolis for the last decades: state, trends, prognosis, methods of screeningevaluation. (Doctoral Thesis of Biomedical Science), Moscow [In Russian]

Wilson IMG (1975) Mass Medical observations: Review of the problem. In WHO ed. Copy-books of Public Health. Meditsina Publ. (tr. by Andreeva MP), 9-31 [In Russian]

Received: March 15, 2005

Accepted: March 23, 2005

Correspondence to: Dr. Yu. A. Yampolskaya, Malyi Kazennyi per., 5, Moscow105064, Russia

e-mail: skoblina@niigd.ru 